\title{
DELAYED RE-FORMATION OF ANTERIOR CHAMBER AFTER TREPHINE OPERATIONS*
}

BY

\section{R. NACCACHE}

Beirut, Lebanon

DELAYED re-formation of the anterior chamber is a frequent complication of trephine operations for the relief of glaucoma, especially Elliott's operation. This complication is a very serious one which, if not relieved, leads to loss of the eye.

Spaeth (1944) discusses this complication but does not describe a treatment for it. Stallard (1946) recommends injection of normal saline into the anterior chamber through the trephine hole under a conjunctival tunnel. Duverger and others (1950) advise cauterization of the conjunctiva with actual cautery.

Neither method has been successful in our hands. Cauterization with actual cautery leads to perforation of the conjunctiva and fistulization. Stallard's procedure fails because the normal saline regurgitates under the flap and is resorbed.

We have tried a simple technique which may be carried out under local

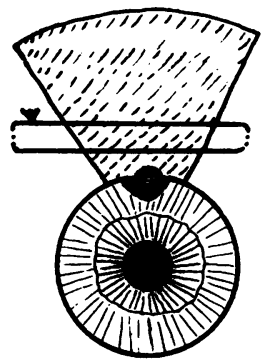

FIGURF.-Suture tied across conjunctival flap. anaesthesia, either alone or in addition to Stallard's.

\section{Technique}

A silk conjunctival thread No. 1 is placed horizontally a few millimetres above the trephine hole and over the conjunctiva. The thread is firmly anchored at both ends to the sclera in the fashion of a double mattress suture. The two anchoring points are placed beyond the conjunctival flap (Figure). The thread is tightly drawn and tied by a double surgical knot.

The curvature of the eye will keep the thread firmly pressed on the sclera through the conjunctiva, thus preventing the aqueous from reaching the area of resorption created during the trephine operation. It is possible to control the resorption of aqueous by placing the thread at different heights above the trephine hole.

If desired, this stitch can be put in place before the injection of saline into the anterior chamber and tied by an assistant when the cannula is withdrawn at the end of Stallard's operation. This will prevent regurgitation of normal saline.

After the suture has been placed in position the anterior chamber re-forms in $\mathbf{4 8} \mathrm{hrs}$. The suture is retained two or three days longer to allow firm anchorage of the conjunctiva. The eye remains somewhat red and irritated as long as the suture is retained, but not enough to be troublesome to the patient.

\footnotetext{
* Received for publication March 26, 1952.
} 
We have used this method with success during the last three years, even in cases where other methods have failed. Of course the anterior chamber must not be allowed to remain empty for too long a period. We believe that if there has been no re-formation of the chamber ten days after the operation, one should not hesitate to apply this simple but effective suture.

\section{REFERENCES}

Duverger, C., Velter, E., and Brégeat, P. (1950). “Thérapeutique Chirurgicale Ophtalmologique ", 2nd ed., p. 318 . Masson, Paris.

Spaeth, E. B. (1944). "Principles and Practice of Ophthalmic Surgery", 3rd ed., p. 762. Lea and Febiger, Philadelphia.

Stallard, H. B. (1946). “Eye Surgery ”, 1st ed., p. 298. Wright, Bristol.

\section{NOTES}

ON the occasion of the Joint Annual Meeting of the British Medical Association and the Irish Medical Association in Dublin on July 8, 1952, the National University of Ireland conferred the degree of M.D. honoris causa upon Sir Stewart Duke-Elder, K.C.V.O., F.R.C.S.

MR. J. H. DoggarT, F.R.C.S., has been co-opted to the Council of the Royal College of Surgeons of England as the representative of the Faculty of Ophthalmologists for the session 1952-53.

Mr. F. W. LAw, M.D., F.R.C.S., has been elected Master of the Oxford Ophthalmological Congress in succession to Dr. F. A. Anderson.

\section{FACULTY OF OPHTHALMOLOGISTS}

THE Council of the Faculty of Ophthalmologists wishes to stress the importance of medical men keeping in mind the danger of visual disabilities in drivers of motor vehicles. Although the legal restrictions on driving refer only to defects in central vision there are potential dangers in other visual defects, such as night blindness and gross restriction of the visual fields. Patients suffering from such defects should either be warned about the need for care in driving, or (if the defect is serious) they should be emphatically advised not to drive at all. 